\title{
LA MERINDAD DE BUREBA Y RIOJA EN LA EDAD MEDIA (SIGLO XI - PRIMERA MITAD DEL SIGLO XIV)
}

\author{
Ana Antoñanzas \\ Universidad de La Rioja
}

La zona en la que se centra el estudio de esta organización territorial corresponde a un área que hoy es la suma de varias identidades geográficas: la Bureba, la zona de Pancorbo, la cuenca del río Tirón, en la provincia de Burgos; y, las cuencas de los ríos Oja y Najerilla, en La Rioja.

\section{La situación territorial}

El legado territorial de Sancho "el Mayor" hace que su hijo mayor y legítimo García "el de Nájera" reciba en herencia, además del núcleo central del reino, la franja oriental del antiguo condado de Castilla: por el sur hasta los Montes de Oca, cerrando toda la Bureba y Álava. Fernando, el segundo, hereda el resto del antiguo condado de Castilla, el territorio situado al oeste y al sur del Arlanzón hasta Burgos, el que se extiende al oeste y al norte de esta ciudad (lo que hoy es el partido judicial de Sedano). A los territorios de García se añadirían después de la batalla de Tamarón, las tierras de Castilla la Vieja'. Nominalmente, la denominación "Bureba" como un territorio político-administrativo no la encontraremos hasta el año $1042^{2}$.

Las consecuencias de otra batalla iban a repercutir en una nueva reorganización del territorio.

Tras algunos incidentes entre ambos hermanos ${ }^{3}$ que desembocaron en la batalla de Atapuerca en 1054, donde moriría el rey pamplonés, Castilla recu-

1. SERRANO, L., Cartulario de San Millán de la Cogolla. Madrid,1930, docs. 112, 113, 124, 125.

2. GARCÍA TURZA, FJ., Documentación medieval del monasterio de Valvanera. (siglos XI al XIII). Zaragoza, 1985. doc. 8.

3. SÁNCHEZ CANDEIRA, A., Castilla y león en el S.XI. Estudio de reinado de Fernando I,edic. R. MONTERO TEJADA, Madrid 1999, pp. 128, 129, 130, 148. 
peró no sólo los territorios cedidos a fines de 1037, sino casi toda la Bureba y una gran parte de Montes de Oca. En 1058 la frontera occidental del reino de Pamplona queda formada por el triángulo que forman las fortalezas de Haro, Pacorbo y Término, con un punto de vanguardia que representa el dominio de Ribarredonda, situada a seis kilómetro al oeste de Pancorbo ${ }^{4}$.

Por su parte Sancho IV Garcés reconocerá al menos aparentemente la situación de hecho pues en ninguno de sus documentos correspondientes al período de 1054-1058 se titulará rey en Castilla la Vieja y solamente hará constar su dominio sobre Pamplona, Nájera Álava y Pancorbo, a lo cual agrega a veces la indicación de que Fernando reinaba en León y en Castilla ${ }^{5}$.

Tras la victoria en Atapuerca, Fernando convocó un concilio que se reunió en Coyanza, hoy Valencia de don Juan, donde se puso de manifiesto el nuevo papel hegemónico desempeñado por el rey sirviendo como inauguración de una fase nueva de gobierno.

En el orden político, el concilio representa la finalización de todo un proceso de reorganización interior realizado por el rey contra los desmanes de la nobleza, de los señores, e incluso contra las extralimitaciones de los funcionarios reales. Al mismo tiempo desarrolla una reforma en la administración que supone a largo plazo una obra de más alcance.

Para Sánchez Candeira, su proyecto debió consistir en "convertir los condados en simples tenencias, que serían gobernados por un conde o por un simple infanzón" El gobierno de amplias regiones encomendado a personajes no pertenecientes a la alta nobleza, suponía una serie de ventajas como que al no poseer grandes riquezas, no se hallaba en situación de oponerse a la voluntad del rey y lo que es más importante, no convertiría en hereditario el cargo que desempeñaba.

Las reformas las introduce lentamente aprovechando coyunturas favorables que le permitieran Ilevarlas a cabo sin colocarse de una forma clara frente a la nobleza leonesa.

Y siguiendo a Sánchez Candeira, este sistema se revela claramente en Portugal: gobernaba este condado la familia de Gonzalo Menéndez y un descendiente, el conde Menendo Núñez lo es hasta su muerte hacia 1054. Es entonces cuando el rey, alegando la juventud de su hijo, encomienda el gobierno a varios infanzones, siendo mayorino del rey en 1058 Diego Tructesíndez. Este mismo sistema fue aplicado en la región del Bierzo, "que había sido gobernada durante el reinado de Vermudo III por el conde Pedro Froilaz". En 1063 al frente está Pelayo Cítiz, un simple infanzón con el título de "Maiorinus totius Bercido", seña-

4. UBIETO, A., Cartulario de San Millán de la Cogolla (759-1076). Valencia, 1976. doc. 298.

5. SERRANO, L., Cart.S. Millán, docs, 159, 160 y 161. 
lando con esta frase la amplitud de los territorios sometidos a su autoridad ${ }^{6}$. En el mismo documento aparece Jimeno Velázquez como merino en Luna.

Pero si esto ocurría en el territorio leonés, en Castilla podemos ver cómo en 1061 aparece Flaíno Oriolez como merino in Borobia ${ }^{7}$.

Este personaje creemos que pudiera tener relación de parentesco con García Oriol, miembro de la curia pamplonesa en $1040^{\circ}$, porque consideramos, ante la ausencia de más información, que el "señor Oriol" Ilegaría a instalarse en esta zona convirtiéndose en un personaje de considerable entidad. Ante los cambios administrativos introducidos por el rey Fernando, un descendiente suyo habría adquirido suficiente posición para que fuese nombrado merino de un territorio. ¿Qué mejor que poner al frente a un personaje que aunque de origen navarro, estaba vinculado a él y que posiblemente le mostró fidelidad antes de Atapuerca?

La Bureba se convierte en el escenario de su política expansionista, sabiendo aprovechar las diferencias surgidas con su sobrino el rey pamplonés, y administrativa. A diferencia de los antiguos condados leoneses, este territorio irredento, pasa a ser controlado directamente por el rey poniendo al frente a su merino. Por lo que consideramos que es el primer territorio del reino castellano en el que está al frente un oficial regio con funciones jurisdiccionales.

En el año 1067 Flaíno Oriolez es dominante en Tedeja9 y junto a él se encuentra Galindo Bellacoz. Este último había gobernado en Tedeja poco después de su ocupación por los castellanos en $1055^{10}$, pues la actitud de Galindo y su hermano debió favorecer la conquista de todas las tierras situadas al margen derecho del Ebro, hasta Lantarón, perdiendo el reino pamplonés su dominio en Arreva, Tedeja y Trespaderne. El rey Sancho seguía una política conti-

6. BLANCO LOZANO, P., Colección diplomática de Fernando I (1037-1065). León, 1987, doc. 67 , pp 173-175.

7. SERRANO, L., Cart.S. Millan. docs.170 y 167.El documento n 167 , p. 177, de Serrano, (Bec. Fol. 135- Colec. № 175) ha sido publicado por UBIETO S. Millán..., con nº 280, p. 273 Becerro, fol. 135-135 vuelto (Gótico, fol. 101, Colección, n 175) con fecha 1051.

Copia B: Arch. S. Millán, Becerro Galicano, fol. 135r-v, copia fines S. XII, carolina, con fecha 1051.

Copia C: Arch. S. Millán, Colec. Minguella, n. 175, copia S. XVIII, con fecha 1061, tuvo como fuente el desaparecido Becerro Gótico, fol. 101.

BLANCO LOZANO, P., Colección diplomática de Fernando I..., pone la fecha de 1061, doc. 56, p. 154; exponiendo que: "El copista del Becerro Galicano omitió una X en la expresión de la era, que sí reflejó, en cambio, el amanuense de la Colec Minguella al trasladar esta escritura del Becerro Gótico.

8. RODRIGUEZ DE LAMA, I., Colección Diplomática Medieval de La Rioja. T.II, Logroño, 1992, doc. 3:"señor Garsea Oriol cum Arresa et Virbesica cum tota sua pertinentia".

9. ALAMO, J. del, Colección diplomática de San Salvador de Oña (822-1284), T.I (8221214). Madrid, 1950, doc. 53, pp 90-92.

10. SÁNCHEZ CANDEIRA, A., Castilla y León, s.XI..., p.154. 
nuista también en la administración conservando a los mismos hombres que habían mostrado fidelidad a su padre, el rey Fernando.

\section{El proceso de formación de las merindades menores. Finales del s. XI a finales del s. XII}

Durante el reinado de Alfonso VI vuelven a aparecer los merinos territoriales siguiendo los intentos centralizadores de la política de su padre pero "todavía no se ha producido un auténtico desarrollo de la administración central de la monarquía, existía una cierta indefinición en la adscripción de los oficiales a sus cargos"11.

La Bureba seguirá configurándose como un distrito administrativo, y ya no veremos al frente a un merino sino que es considerada como una tenencia específica. En el 1089 aparece citada dicha tenencia: "Illa cometissa de dompna Sancia in Petralata et in Boroua"12. Doña Sancha era la viuda de Gonzalo Salvadórez, hijo a su vez de Salvador González el senior de Arreba en $1040^{13}$. Su hijo, el conde Gómez, tendrá el año siguiente las tenencias "in Cereso et in Ponticurbo et in Petralata"14. Desde 1102 a 1106 será tenente en Bureba: "Comessanus (sic) comes tenente Borouiam"15 y en 1106 lo veremos como "dominante Cereso et Ponticurbo et tota Petralata"16. Posteriormente en un documento datado en $1077^{17}$, que considera Martínez Díez que debe fecharse en $1107^{18}$, podemos ver todavía a "Gomesanus comes in Borobia".

En el 1076 el territorio riojano pasaba a formar parte del reino de Castilla y una de las formas de afianzar el dominio político del rey en este territorio fue la de nombrar como tenentes en Nájera a Martín Sánchez ${ }^{19}$ y posteriormente a Pedro Ibáñez ${ }^{20}$. Personajes estos que fueron merinos en Castilla ${ }^{21}$.

Antes de ser nombrado tenente en Nájera, Martín Sánchez era merino en Burgos y en Cerezo cuando actúa como testigo en $1077^{22}$ en un mandamiento

11. ÁLVAREZ BORGE, I., Monarquía feudal y organización territorial: alfoces y merindades en Coudilla (siglos X-XIV). Madrid, 1993, p. 151.

12. ÁlAMO, J. del, Col. dipl. Oña..., doc. 95.

13. RODRIGUEZ DE LAMA, I., Colec. Diplom. Mediev. Rioja, doc. 3.

14. SERRANO, San Millán, doc. 278.

15. ÁlAMO, J. del, Col. Dipl. Oña..., docs. 115, 124.

16. LEDESMA, Ma . I. Cartulario de San Millán de la Cogolla. Zaragoza, 1989, doc. 313.

17. LEDESMA, San Millán, doc. 5.

18. MARTíNEZ DÍEZ, G., "La Bureba como distrito administrativo: la tenencia", en Historia Administrativa y Ciencia de la Administración Comparada. Barcelona, 1990, p. 4285. El autor considera que la cláusula "Adefonsus totius Ispanie rex" no puede datarse en 1077 sino después de 1085.

19. GARCÍA TURZA, F.J., Doc. Valvanera, doc. 84.

20. RODRIGUEZ R. DE LAMA, Col. Dipl. Med. Rioja. T.II, doc. 37.

21. ÁlVAREZ BORGE, I., Monarquía feudal... Cuadro II. Relación merinos territoriales de Castilla. p. 212.

22. LEDESMA, San Millán, docs. 4 y 8. 
real para que se cumplieran las penas impuestas a un vecino de Cihuri por la muerte del merino Fortún Manso.

En 1089 es Pedro Ibáñez el delegado del poder regio ante el abad de San Millán ${ }^{23}$.

Probablemente estas actuaciones de los merinos territoriales en las zonas riojanas, "fue uno de los caminos adoptados para afianzar el dominio político del rey de Castilla en esos territorios" 24 .

Estas nuevas atribuciones judiciales y fiscales que se extienden a los nuevos territorios irán definiéndose gradualmente, "de la ocupación de la tenencia por los merinos se pasa a la integración del territorio en el ámbito de actuación del merino territorial, yuxtaponiéndose a la tenencia, que se sigue conservando"25. El ejercicio del cargo de merino territorial Ilevaba aparejado también el ejercicio de otras formas de atribuciones de poder personal: "su capacidad de ejercer un cierto dominio sobre la Rioja recién conquistada no dependía tanto de que administrativamente se hubiera incluido a estas zonas en su territorio de actuación, sino del poder que pudieran ejercer allí a través de otras fórmulas como la tenencia"26.

En el año 1128 Alfonso VII se titulaba rey en Castilla, Pamplona, Aragón, Sobrarve y Ribagorza y entre los que le acompañan se encuentra Lope Iñiguez como tenente "in Borobia et in Alfaro"27. El mismo personaje que seguiría siendo tenente en la Bureba en 1130, pero esta vez al lado de "el Batallador" 28 .

Lacarra considera que las tenencias en esta época son concesiones feudovasalláticas en tanto que parecen ser concesiones pactadas entre los nobles del reino, con entrega de beneficios a cambio de ayuda militar, sobre todo en el momento de la gran expansión territorial de Aragón ${ }^{29}$.

En 1131 Alfonso VII ya había recuperado la Bureba porque es tenente Rodrigo Gómez ${ }^{30}$, el hijo de Gómez González el último tenente bajo el reinado de Alfonso VI. Es de suponer que en los enfrentamientos habidos entre castellanos y aragoneses hubiera magnates que tomaran partido por uno u otro reino. Vimos anteriormente como en la Bureba se situaba al frente a un miembro de la curia del rey aragonés cuando la zona estaba bajo su influencia. En este momento el rey leonés vuelve a poner en el cargo a uno de sus partidarios.

23. LEDESMA, San Millán, doc. 189, "In merinitate de Petro lohanne".

24. ÁLVAREZ BORGE I., Monarquía feudal..., p. 156.

25. ÁLVAREZ BORGE, I., Monarquía feudal..., p. 157.

26. ÁLVAREZ BORGE, I., Monarquía feudal..., p. 157.

27. RODRIGUEZ R. DE LAMA, Colec. Dipl. Med. Rioja T.II, doc. 93.

28. RODRIGUEZ R. DE LAMA, Colec. Dipl. Med. Rioja T.II, doc. 98.

29. LACARRA, J.M ${ }^{a}$., "Honores y tenencias en Aragón (siglo XI)", en Colonización, parias, repoblación y otros estudios. Zaragoza, 1981, pp. 184 -185.

30. OCEjA GONZALO, I., Documentación monasterio de San Salvador de Oña. Burgos 1983, doc. 49. 
Su reinado, como los de sus antecesores, supone "la fase inicial de desarroIlo del señorío jurisdiccional del rey", reflejándose "en la imprecisión que presentan los oficiales que ocupan los cargos de merinos territoriales" ${ }^{\prime \prime 1}$. En 1152 era dominante en la Bureba Gonzalo Ruiz pero ahora se sitúa junto a él Alfonso Muñoz como "merino del emperador", actuando en una conveniencia entre el abad de San Millán y el concejo de Santa María de Rivarredonda ${ }^{32}$. En este caso se comprueba como el ámbito jurídico del rey se ve reforzado en la figura del merino. Esta misma actuación se puede ver en Pedro Fortuñones de Royuela, adelantado del rey en $1155^{33}$, cuando actúa en un litigio entre los vecinos de Villar de Torre y los de Madriz por la posesión de una dehesa y ante la presencia del conde Lope dominante en Nájera.

En el 1156 el tenente de la Bureba era Gonzalo Rodríguez ${ }^{34}$ cuando por orden del rey se realizó una pesquisa para deslindar los términos de Padrones de Bureba y Poza de la Sal. Entre los pesquisidores se encuentra el merino Ferrandum Iohannem.

En 1170 seguía como "dominante Borovie Gonzalvo Roderici"35. Junto a él aparece como merino Oriolo. Todavía seguimos viendo el cargo de merino sin definición territorial.

Este personaje, Oriol, consideramos que puede descender del primer merino de Bureba, Flaíno Oriol que se documentaba en 1061 y siendo a su vez miembros de la familia de propietarios que la documentación nos presenta y que exponemos en el siguiente cuadro ${ }^{36}$ :

31. ÁlVAREZ BORGE, I., Monarquía feudal..., pp 157-158.

32. LEDESMA, Cart. San Millán, doc. 391, p. 276.

33. LEDESMA, Cart. S. Millán, doc. 395.

34. ÁLAMO, J. del, Col. Dipl. Oña, doc. 222.

35. LEDESMA, Cart. San Millán, doc. 413.

36. ÁLAMO, Oña. docs. 44, 84. LEDESMA, S. Millán. docs. 9, 24, 56, 95, 100, 108, 143, 167, $187,191,201,229,266,501$. 


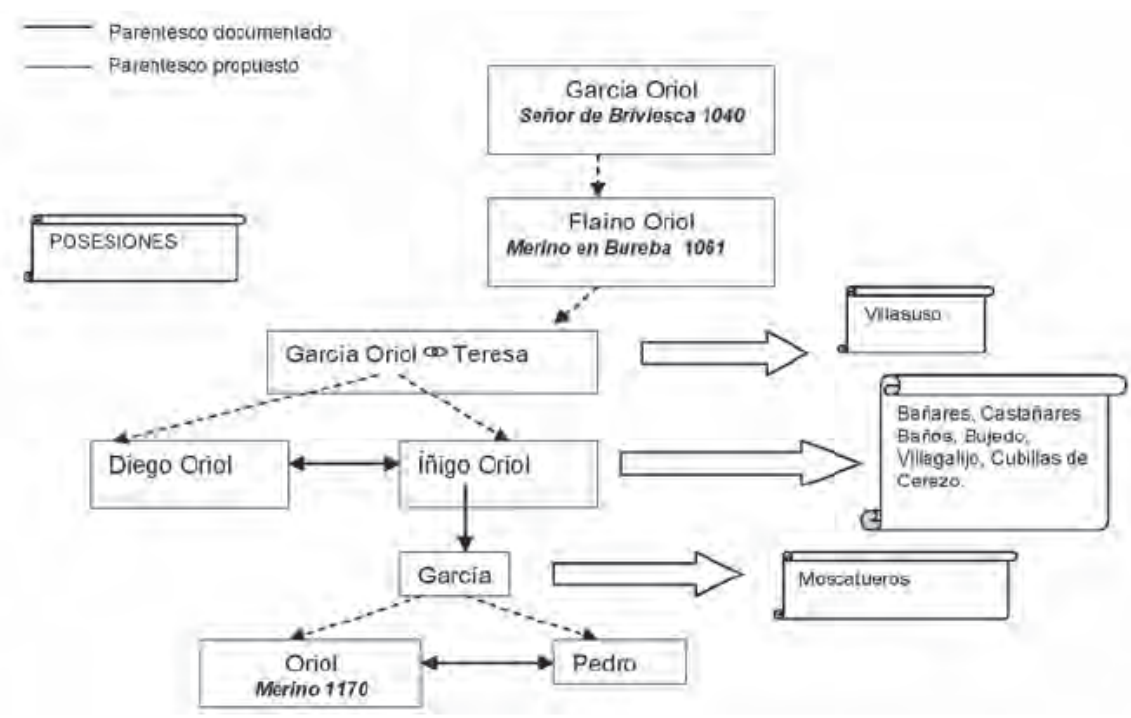

En 1177 se concede el Fuero de Miranda de Ebro. Su artículo 38 comienza de esta manera: "omnes homines de terra lucronii, aut de nagera, aut de rioga,..." ${ }^{\prime 37}$. Representan a tres identidades territoriales diferenciadas que con el paso del tiempo formarán la Ilamada Rioja Alta. Pero el hecho más importante para nosotros es que $\underline{\text { Rioja }}$, ha dejado de ser un espacio de valle ${ }^{38}$ para convertirse en un espacio territorial diferenciado y con identidad propia.

A partir de esta fecha podemos ir viendo cómo los cargos van teniendo un contenido específico. La definición será gradual cómo también lo será la de los oficiales y los distritos que irán coexistiendo, al principio con las tenencias y los tenentes, hasta ser sustituidos completamente.

En 1178 un documento nos habla de la pesquisa practicada por "Oriolo, tunc temporis in tota Borovia per mandatum regis maiori merino ${ }^{1 / 39}$ actuando en una disputa entre el monasterio de San Millán y el concejo de $\mathrm{St}^{\mathrm{a}} \mathrm{M}^{\mathrm{a}}$ de Ribarredonda. Para Álvarez Borge esta definición del merino, "puede hacer referencia... a la posición superior de Oriol sobre otros merinos de la zona y, por otro lado, su vinculación directa al rey, no al merino mayor de Castilla"40. Entre los testigos

37. MARTÍNEZ DÍEZ, G., Fueros locales en el territorio de la provincia de Burgos. Burgos, 1982, XXII, pp.158-165.

38. GARCÍA DE CORTÁZAR, J.A., “Organización social del espacio en la Rioja cristiana en los SS. X y XI", en Historia de la ciudad de Logroño, tomo II. Logroño, 1995, pp. 55-168.

39. GONZÁLEZ, J., El reino de Castilla en la época de Alfonso VIII. Madrid, 1960, T. II, doc. 294 , p. 483.

40. ÁLVAREZ BORGE, I., Cambios y Alianzas. La política Regia en la frontera del Ebro en el reinado de Alfonso VIII de Castilla. (1158-1214). C.S.I.C. Madrid, 2008, pp. 359, 360. 
figura "Petrus germanus" como merino en Bureba. Con toda probabilidad pudiera ser su hermano, merino dependiente del merino mayor de la Bureba.

En 1181 aparece Martin de la Follia como "maiorinus in tota Borouia"/41 en la venta de unas salinas en Poza al monasterio de Oña.

Ese mismo año Oriol es merino del rey además de tenente del castillo de Cellorigo efectuando una pesquisa en el valle de Fontanillas ${ }^{42}$. Álvarez Borge ha interpretado que Martín de la Follía, "en tanto que merino de Bureba, dependiera de Oriol que continuaría siendo merino mayor, de manera similar a Pedro germanus".

En 1183 aparece Pedro García de Lerma como "dominante in Granon et in tota rio d'Oia" ${ }^{\prime \prime 3}$, y junto a él, el merino Fortun García de Ayuela que, a pesar de no darnos mas información sobre su función territorial, pero al aparecer junto al tenente de Rioja, podría ser considerado como el primer merino de Rioja.

En 1185 "Borreco regis merinus"/44 está presente en la toma de posesión de una tierra que el monasterio de San Millán había comprado al concejo de Haro, el tenente es Diego López. Y es el mismo merino que al año siguiente es testigo de una pesquisa que hizo don Oriol "merino regis" ${ }^{45}$ en el pleito que mantenían los de Arce con los monjes de Bujedo sobre los derechos de unas tierras.

Estos dos merinos, Oriol y Borrego aparecerán en 1188 junto a Diego López en una donación que hace éste a los monjes de Bujedo pero no como merinos sino como, "praetoribus honoris Didaci Lupi"46. Se nos escapan las razones de su vinculación personal no así las de Borrego con los Haro que venían de unos años atrás ${ }^{47}$. La relación de estos merinos con Diego López de Haro "nos indica que el nuevo sistema de la administración territorial en merindades no surge ajeno a los intereses de los nobles" ${ }^{\prime 4}$, sobre todo en la zona que nos ocupa.

En 1191 es testigo "Lupus Moggo merino in tota Rivogia"49 de una donación. Constituye el documento la primera manifestación de Rioja como merindad y su primer merino que como tal aparece, además del único dato sobre su actuación.

Oriol vuelve a aparecer unos años mas tarde. En 1192 es testigo en varias actuaciones en relación al monasterio de Oña ${ }^{50}$. En el mismo actúa como testi-

41. ÁlAMO, J. del, Col. Dipl. Oña, doc. 252, p. 300.

42. LEDESMA, Cart. San Millán, doc. 436.

43. UBIETO, Cartularios (I, II y III) de Santo Domingo de la Calzada). Zaragoza, 1978, doc. 61.

44. LEDESMA, Cart. San Millán, doc. 447.

45. LEDESMA, Cart. San Millán, doc. 449.

46. RUIZ DE LOIZAGA, S., Libro Becerro de Santa María de Bujedo de Candepajares (11681240). Miranda de Ebro, 2000, doc. 53.

47. ÁLVAREZ BORGE, I., Cambios y Alianzas...p. 362.

48. ÁLVAREZ BORGE, I., Cambios y Alianzas...p. 363.

49. LEDESMA, Cart. San Millán, docs. 464, 465.

50. ÁlAMO, J. del, Col. Dipl. Oña, docs. 297, 301. 
go y merino del rey en dos ventas, en Ciriñuela y en Santa María de Ribarredonda, al monasterio de San Millán y en la pesquisa que hizo en Ameyugo el abad de Bujedo ${ }^{51}$.

En 1193 don Oriol hace un apeo en Terroves (hoy jurisdicción de Valderrama) por mandato del rey Alfonso ante la querella del abad de Bujedo porque los pobladores de las villas limítrofes, Valderrama, Cubilla, Miraveche y Cascajares de Bureba, hacían uso del término donado al monasterio ${ }^{52}$.

En diciembre de 1193 aparece como merino del rey en Bureba Don lague en la carta foral que el abad de Oña da a los hombres de Solduengo y de Quintana Marzán, y uno de los testigos es don Oriol ${ }^{53}$. En febrero del año siguiente también es testigo de la confirmación por parte de doña Urraca López, hermana de Diego López, que hace al monasterio de Oña de los montes de Piedralada, que habían sido concedidos por Alfonso VIII al monasterio un año antes ${ }^{54}$.

En 1198 el concejo de Herrera de Valdivielso acepta el resultado de la pesquisa efectuada por don Oriol, en la disputa que tenía con el monasterio de Oña por el monte del lugar ${ }^{55}$. Su actuación ya no es como merino. Su presencia pudiera estar justificada porque, como hemos podido comprobar, es un propietario destacado en la zona que está presente, testificando, en numerosas actuaciones del monasterio. Un último documento en el que aparece Oriol está fechado en 1207 y es la confirmación al concejo de Pedroso de sus términos ${ }^{56}$. En él se alude a: "vobis terminum per subscripta loca, sicut Oriolo, quondam merinus meus...". El texto alude a un tiempo pasado por lo que podríamos fechar su actuación como merino hacia 1193.

Por lo que hemos podido comprobar, don Oriol después de figurar como merino de Bureba, actuaba como oficial del rey en diversos lugares tanto de Rioja como el valle del Najerilla. Su actividad se desarrollaba en base a la importancia del personaje en vista de sus propiedades. La documentación consultada nos permitirá comprobar y exponer mas adelante como esa familia seguirá manteniendo su influencia en la Bureba.

Por lo que respecta a la Rioja en el mismo año de 1207 aparece como testigo Diego Martínez "adelantado dominun regis" ${ }^{57}$ del que no poseemos mas información. Sin embargo en 1211 aparecen como firmantes el merino del rey

51. LEDESMA, Cart. San Millán, docs. 469, 470, 472.

52. RUIZ DE LOIZAGA, S., Lib. Becerro S.M Bujedo, doc. 64.

53. ÁLAMO, Juan del, Col. Dipl. Oña, doc. 305.

54. OCEJA, I., Doc. Mon. Oña, doc. 80.

55. ÁlAMO, Juan del, Col. Dipl. Oña", doc. 316.

56. GONZÁLEZ, J., El reino de Castilla. Alf. VIII, doc. 807.

57. UBIETO, Cart. Sat ${ }^{\circ}$. Dom. Calz., doc. 92. 
en Castilla García Ruiz Barba, "sub eo Petro Didaci, maiorino Borovia et Rivogia ${ }^{1 / 58}$ lo que nos permite exponer que las merindades de Bureba y Rioja se han constituido en una sola unidad administrativa integrada en la Merindad Mayor de Castilla ya plenamente constituida. La unión administrativa de las dos merindades todavía nos es desconocida pero no debemos olvidar que Diego López de Haro controlaba estos territorios: "dominante in Castella Vetula, et Borovia, Rigovia et Naiera, Gronio et Calagurra" y que pudiera intervenir en una consideración administrativa lo que repercutiría en el nombramiento de los oficiales. De este merino no poseemos más noticias sobre su actividad excepto la de establecer un parentesco con el adelantado anterior Diego Martínez y que podríamos considerar como su sucesor en el cargo con más atribuciones territoriales.

En resumen; durante el siglo XII se ha ido desarrollando un proceso de expansión territorial castellano de forma discontinua. Por el este, la Rioja, zona fronteriza disputada desde la muerte de Sancho el Mayor que pasó definitivamente al reino castellano a partir de 1173 .

Las formas de organización política, precisamente, derivan de ese proceso de expansión territorial que se produjo en un largo intervalo de tiempo. Principalmente esa organización se sustenta de forma directa sobre la figura del rey. Las instituciones de gobierno están poco desarrolladas, pero en este espacio de tiempo vemos que existe una clara evolución, que hace que esas instituciones "sobrevivan" al concepto patrimonial del territorio y sean más precisas sobre todo en la administración de justicia y la fiscalidad. En consecuencia los cargos y los oficios son cada vez más abundantes y sobre todo más determinados.

\section{Plenitud y desarrollo de las merindades menores. El siglo XIII y primera mitad del siglo XIV}

Si a finales del reinado anterior la Merindad de Bureba y Rioja estaban unidas bajo un mismo oficial pudiendo llevarse a cabo esta unión bajo la tenencia de los territorios al norte del Duero por Diego López de Haro, muerto en 1214, es en el reinado de Fernando III cuando se produce el enfrentamiento nobiliario y en consecuencia el nombramiento real de oficiales no procederán de los grandes linajes, cuando la documentación nos muestra que territorialmente nuestra merindad ha vuelto a constituirse en dos unidades diferenciadas. Lope Díaz de Haro, hijo de Diego López de Haro aparece como dominante solamente de la Bureba en 1219 y seguirá siéndolo hasta $1233^{59}$.

El primer nombre que nos aparece es Don Nuño de Aguilar que en 1222 es Ilamado "el adelantado" 60 . El título no lleva acompañado ninguna adscripción

58. UBIETO, Cart. Sat ${ }^{\circ}$ Dom. Calz., doc. 100.

59. ÁlAMO, Oña, docs. 423, 469.

60. LIZOAIN, J.M., Documentación del Monasterio de Las Huelgas de Burgos (1116-1230). Burgos, 1985, doc. 173. 
territorial pero su significado es político por cuanto al año siguiente es denominado "iudex maior regis in Borovia" pudiera estar causada por los inicios de un reinado que además Ileva aparejado una reestructuración territorial.

El personaje con apellido indicativo de su procedencia, "de Aguilar de Bureba" es una muestra de la política seguida por el rey, nombrando a oficiales allegados al territorio, pertenecientes a la nobleza regional.

Antes de su nombramiento ya era considerado persona de relieve pues lo vemos de testigo en la pesquisa de heredades de Tamayo ordenada por Lope Díaz de Haro en $1218^{62}$. No obstante, su cargo le debió repercutir cierta consideración en la zona por la frecuencia con que lo encontramos asumiendo la fianza en documentos de compraventa ${ }^{63}$. Por lo que respecta a sus posesiones muestran un patrimonio limitado y de dominio disperso. La venta de dos tierras de relativa poca importancia en diferentes fechas: un solar en Cubo y unas tierras de labranza en Calahorrilla ${ }^{64}$, parece confirmarlo.

En 1237, el Adelantado Gonzalo González realiza una pesquisa sobre la propiedad del monte de Valdefornos disputada entre el monasterio de Oña y los diviseros de Quintana Opio ${ }^{65}$.

En la Merindad de Rioja nos aparece el primer merino en este reinado en el 1224, Diego Martínez de Zarratón, Adelantado de Rioja, haciendo una pesquisa en Santa María de Redecilla, acompañado del abad de Santo Domingo y del merino de Lope Díaz de Haro ${ }^{66}$. De este personaje, que no poseemos mas datos, es preciso destacar el topónimo de su procedencia "de Zarratón", se trata de un personaje de una población perteneciente a la Merindad de Rioja. Álvarez Borge plantea una actuación conjunta de estos dos merinos, Diego Martínez de Zarratón y Nuño de Aguilar, como sus antecesores Borrego y Oriol, y "vinculados al magnate más poderoso de la zona"67.

En 1239 era Adelantado en Rioja Ferrán Ruiz de Fervías ${ }^{68}$ y en 1242 Ferrando Díaz de Grañón se titulaba Merino de tierras de "Nagera e de Rioia"69. Esta doble denominación territorial nos muestra la entidad que poseía Nájera. A

61. ÁlAMO, Oña, doc. 434.

62. ÁlAMO, Oña, doc. 421.

63. PÉREZ DE TUDELA, M.I., El monasterio de Vileña en sus documentos. El códice del A.H.N. Madrid, 1977, doc. VI. En la introducción se hace referencia expresa sobre Nuño de Aguilar. Docs: XXXIX, XLIV, XXXII, LIV, XXVIII, XXI y LXXVIII, XXIX.

64. PÉREZ DE TUDELA, M.I., Vileña, docs. XXVIII y LXXIX respect.

65. GONZÁLEZ, J., Col. Dipl. Fernando III, T. III doc. 601.

66. UBIETO, Cart. Sant ${ }^{\circ}$. Domingo doc. 134.

67. ÁLVAREZ BORGE, I., Cambios y Alianzas...p. 370.

68. RODRÍGUEZ DE LAMA, I., Colección Diplomática Medieval de La Rioja. Documentos s. XIII. Logroño, 1989, T. IV, doc. 127.

69. RODRÍGUEZ DE LAMA, I., Col. Dipl. Rioja. T. IV, doc. 142. 
Díaz de Grañón lo veremos en 1261 actuando de testigo en la venta de una heredad al concejo calceatense ${ }^{70}$.

Se constatan los oficiales regios claramente en este reinado, que pertenecen a los "sectores intermedios o bajos de la nobleza"71. En la segunda mitad del siglo XIII el panorama será diferente.

Con Alfonso X cambia la política de nombramientos de los merinos mayores que ahora son miembros de la alta nobleza.

En los primeros años del reinado se produjo una primera rebelión encabezada por el infante don Enrique, hermano del rey, y por Diego López de Haro y su hijo Lope Díaz. Quizás sea esta la causa por la que para estas fechas no encontramos a ningún merino en Bureba. En cambio, en la Merindad de Rioja, en febrero de 1257, vemos a Ferrando Díaz de Roias, merino de Rey, "por mano de don Ferrant Goncalvez de Roias, so ermano, merino mayor en Castiella"72. En junio del mismo año es Martinus Petri el merino de Rioja. El mismo documento nos informa que el tenente en Rioja es Nuño González (de Lara) ${ }^{73}$. De estos dos merinos no poseemos más noticias que las referidas.

Pero si las noticias sobre los merinos en esta época, son relativamente escasas, la división administrativa seguía siendo igual que en el anterior reinado. Una carta que en 1269 el rey Alfonso X dirige a los merinos de las merindades de: Burueva et de Roia et de Castilla Uieia et de Valdegouia et de Villadiego et de Asturias de Sancta Yllana,..."74, nos lo confirma.

En 1270 el rey Alfonso X manda a: "Ios nuestros merynos que andan por nos en la meryndat de Burueua e de Rrioia" , que hiciera cumplir el derecho de pastos que poseía el concejo de Santo Domingo, que le llevaba a enfrentarse con los concejos de Ojacastro, Santurde, Santurdejo, Ayuela (despoblado), Gallinero, Bañares, Somsoto (despoblado), Corporales, Pino de Suso (despoblado) y Pino de Yuso (despoblado $)^{75}$. Una relación de lugares en la merindad que nos permite ir configurando un mapa aproximativo. En 1276 el rey dirige una carta al "merino de Bureba y Rioja"n6. La merindad se había vuelto a reunificar bajo un mismo oficial como lo estuviera a principios de este siglo. Las causas se nos escapan por la escasez de datos sobre los oficiales regios que poseemos para este reinado.

70. LOPEZ DE SILANES, C. y SAINZ RIPA, E. Colección Diplomática Calceatense. Archivo Municipal (1207-1498). Logroño, 1989. doc. 4.

71. ÁlVAREZ, I., Monarquía feudal..., p.174.

72. GARCÍA TURZA, C. y GARCÍA TURZA, F. J., Una nueva visión de la lengua de Berceo a la luz de la documentación emilianense del siglo XIII, Logroño, 1996, doc. 56.

73. UBIETO, Cart. Sat ${ }^{\circ}{ }^{\circ}$, doc. 144.

74. ÁlAMO, Oña, doc. 581.

75. LÓPEZ DE SILANES y SÁINZ RIPA, Col. Dipl. Calc. Arch. Mun., doc. 8.

76. CANTERA BURGOS, F. y ANDRÍO GONZALO, J. "Apéndice documental", en Historia Medieval de Miranda de Ebro, Miranda de Ebro, 1991, pp. 307-602, doc. 12. 
En 1277 vemos a Roy Fernández como Merino del Rey de Bureba y Rioja, reconociendo la propiedad del monasterio de Oña, en Villaverde, en la quereIla que el citado monasterio mantenía con Toda Ortiz ${ }^{77}$. Este personaje es el primer merino nominativo que nos aparece en la documentación después de ser reunificada la merindad y pudiera ser el mismo al que estaba dirigida la carta del año anterior. En el año 1279 el rey Alfonso comunica al merino de Bureba y Rioja la partición de villa de Arraya (alfoz de Oca) ${ }^{78}$. El documento no menciona el nombre del merino.

En julio de 1282 vemos en la toma de posesión por el monasterio de Oña de la heredad que tenía Toda Ortiz en Villaverde, al Merino de Bureba y Rioja, Diego Pérez. En el documento se hace mención a los merinos anteriores al citado Diago Pérez: "... los otros merinos que fueron antes de mi,..." ${ }^{\prime \prime 9}$. De lo cual se deduce que desde Roy Fernández hubo dos merinos más.

A comienzos del reinado de Sancho IV, en septiembre de 1284 es Juan González de Bobadilla merino del rey en Bureba y Rioja ${ }^{80}$. Al año siguiente está Pedro García de Leiva, Merino del Rey en Bureba, "por Juan González de Bovadilla"81. El merino de Bureba y Rioja era lo suficientemente importante como para nombrar a un merino subsidiario y ponerlo al frente de "parte" de la merindad o "subrogando competencias en merinos territoriales" ${ }^{82}$ como plantea García Turza. Por otra parte, el Merino Mayor de Castilla era Sancho Martínez de Leiva, lo que nos lleva a suponer cierta complicidad entre la nobleza de la zona para colocar en los cargos públicos a sus parientes.

Más adelante veremos a Juan González de Bobadilla, que será en 1288 y 1289 merino en la Merindad de Santo Domingo de Silos ${ }^{83}$.

En octubre de 1289 el merino de la Merindad de Bureba y Rioja es Gil Pérez de Briones ${ }^{84}$. Aludiendo al pleito que mantenía el concejo de Miranda con García López de Gaceo, este documento es la carta que envía el rey a su merino para hacer que García López se presentara ante el rey en el plazo de 30 días,

77. ÁLAMO, Oña, doc. 666.

78. PEREDA LLANERA, Documentación Catedral de Burgos (1254-1293). Burgos,1984, doc. 157.

79. ÁlAMO, Oña, doc. 722.

80. OCEJA, I., Oña, doc. 254.

81 OCEJA, I., Oña, doc. 287.

82. GARCÍA TURZA, F.J., "Los espacios de poder en La Rioja Medieval", en Los espacios de poder en la España Medieval, XII Semana de Estudios Medievales. Nájera 2001, p. 506.

83. ÁlVAREZ BORGE, I., "Merindades y merinos menores de Silos, Muñó y Castrogeriz. Notas sobre la evolución de la monarquía feudal y la organización territorial en Castilla (12001350)", en III Jornadas Burgalesas de Historia. Burgos en la Plena Edad Media. Burgos 1994. pp. 657- 667.

84. CANTERA BURGOS, Hist. Medieval de Miranda, doc. 43. 
bajo multa de 100 maravedíes. Si no se presentara se debía tomar parte de sus bienes y venderlos para pagar así las costas al personero del concejo.

Posiblemente esta sería su última actuación porque en enero de 1290 el Adelantado de Bureba y Rioja, además de alcalde del rey, es Martín Fernández de Soto $^{85}$, personaje que vemos en esta misma fecha recibiendo rentas de la fiscalidad regia, "pechos de judíos", como vasallo del rey Sancho IV ${ }^{86}$. A Pérez de Briones lo veremos como fiador en 1296 en una venta a la iglesia calceatense ${ }^{87}$ y en 1299 actuará como alcalde sentenciando sobre la propiedad de ciertas heredades que el cabildo calceatense y Juan Sánchez tenían en Castañares ${ }^{88}$.

Martín Fernández de Soto aparece en el documento de 1290 como parte en el pleito que mantenía su hermano Alfonso Fernández con el monasterio de Oña por los bienes que había comprado a su abuelo Pedro Oriol en Navas.

A finales del S. XII hemos observado la vinculación de don Oriol con el monasterio. En los inicios de su fundación es dotado con diversos lugares en la Bureba $^{89}$, y en esos documentos se hace mención a los infanzones de esas villas lo que nos demuestra la existencia de una nobleza local, a la que no dudamos, pertenecía la familia Oriol dada su trayectoria.

A partir del siglo XIII, la documentación muestra ciertos cambios en las relaciones entre el monasterio y la familia Oriol. Ahora los vamos a ver, con cierta frecuencia, vendiendo o disputando antiguos derechos con el monasterio, que no dudamos son causa de un cambio en las relaciones sociales, pero que por alejarse del contenido de nuestro estudio los vamos a obviar, limitándonos exclusivamente a hacer una relación de los miembros de esta familia y sus posesiones $^{90}$ en el siguiente cuadro genealógico que presentamos.

Los documentos nos muestran los testimonios en los pleitos que hasta finales de siglo, estuvieron implicados los hijos, nietos y bisnietos de Pedro Oriol en la demanda de las heredades en Navas. Pero se muestran parcos en el desarrollo de estos litigios y consideramos que esta serie de pleitos por parte de los descendientes de don Oriol y la actuación del merino Martín Fernández de Soto, su bisnieto, estuvieran encaminados a la obtención de bienes del monasterio de Oña

85. OCEJA, Oña, doc. 338.

86. HERNÁNDEZ, F. J., Las rentas del Rey: sociedad y fisco en el reino castellano del siglo XIII. Madrid, 1993, pp. 99,100. Partición de Huete de 1290.

87. LOPEZ DE SILANES, C. y SAINZ RIPA, E., Colección Diplomática Calceatense. Archivo Catedral (1125-1397). Logroño, 1985, doc. 64.

88. LOPEZ DE SILANES, C. y SAINZ RIPA, E., Col. Dipl. Calceat. A.C., docs. 66 y 71.

89. ÁlAMO, Oña, docs. 9 y 12.

90. Tomo III de la Colección Hergueta, sin folio, año 1204. (procede del Becerro Galicano, fol. 245v; Col. Minguella, doc. 496).

CADIÑANOS, El Monasterio de Santa María de Rioseco y su Cartulario, doc. 89.

ÁLAMO, Oña, docs. 429, 434, 450, 644, 719.

PÉREZ DE TUDELA, M.I., El Monasterio de Vileña en sus documentos, docs. I, III, XVI, LV, LXV. OCEJA, Oña, docs. 259, 419, 358, 231, 233. 
por medio de la práctica judicial, estableciendo un nuevo elemento de poder como parte de una estrategia para definir la relaciones de poder locales.

La documentación nos ha permitido hacer un seguimiento somero sobre esta familia, que por sus propiedades e influencias podemos considerarla como nobleza local y que pudiera compartir semejanzas ya señaladas por Martínez Sopena en su estudio en Tierra de Campos $^{91}$ : influencia y arraigo en una zona concreta de cierta extensión de la que poseen propiedades; el concepto de linaje a través de la vinculación del nombre del abuelo como patronímico y, como además en este caso, el sobrenombre del lugar al recaer la línea directa en una fémina; la vinculación a un gran monasterio; el comportamiento señorial con respecto al campesinado. Añadiremos y siguiendo a Martínez Sopena en sus conclusiones, que esta nobleza local sigue permaneciendo en los solares familiares pese a las enajenaciones hechas por alguno de sus miembros y negociando con la institución monástica.

La prematura muerte de Sancho IV ocasiona un período de minoría de edad de su hijo y sucesor, Fernando IV y la regencia de su madre María de Molina, entre 1295 y 1301, que fue muy conflictivo.

La documentación consultada nos muestra este período de crisis. En 1299, Fernando IV urge al Merino Mayor de Castilla, Juan Rodríguez de Rojas, y a los merinos de Bureba y Rioja para que respeten al cabildo calceatense las casas, viñas, heredades y vasallos que le han arrebatado ciertos caballeros y personas poderosas ${ }^{92}$. Estos hechos violentos poseían un carácter más amplio y general ya estudiados por Salustiano Moreta ${ }^{93}$. Para los nobles las "malfetrías" suponían un importante botín por los ingresos y rentas, con el añadido de poder destruir los recursos de sus adversarios, que en este caso es el rey.

Pero si en este documento nos informa sobre los "entramientos" de ciertos nobles en unas heredades que "ha treinta años o mas que lo tovieron de iur e de poder", de los cuales no nos informa de sus nombres como tampoco de los merinos de Bureba y Rioja, nos encontramos, por el contrario, con un documento extraordinario y que ha resultado para nosotros bastante revelador de la crisis que también se veía reflejada en nuestra merindad, el cual nos revela no sólo el nombre de varios merinos de Bureba y Rioja, sino sus actuaciones, viéndose por ello enfrentados a diferentes concejos.

El documento, dividido en varias partes o folios, nos ha llegado, desgraciadamente como ocurre en otros muchos casos, incompleto. Se trata de los agra-

91. MARTínEZ SOPENA, P., La Tierra de Campos Occidental. Poblamiento, poder y comunidad del siglo $X$ al XIII, Valladolid, 1985, p. 567.

92. LÓPEZ DE SILANES, C. y SÀINZ RIPA, E., Col. Diplom. Calceatense. Arch. Catedral, doc. 69.

93. MORETA, S., Malhechores-feudales. Violencia, antagonismos y alianzas de clases en Castilla, s.s. XIII-XIV. Madrid, 1978, pp. 66-67. 


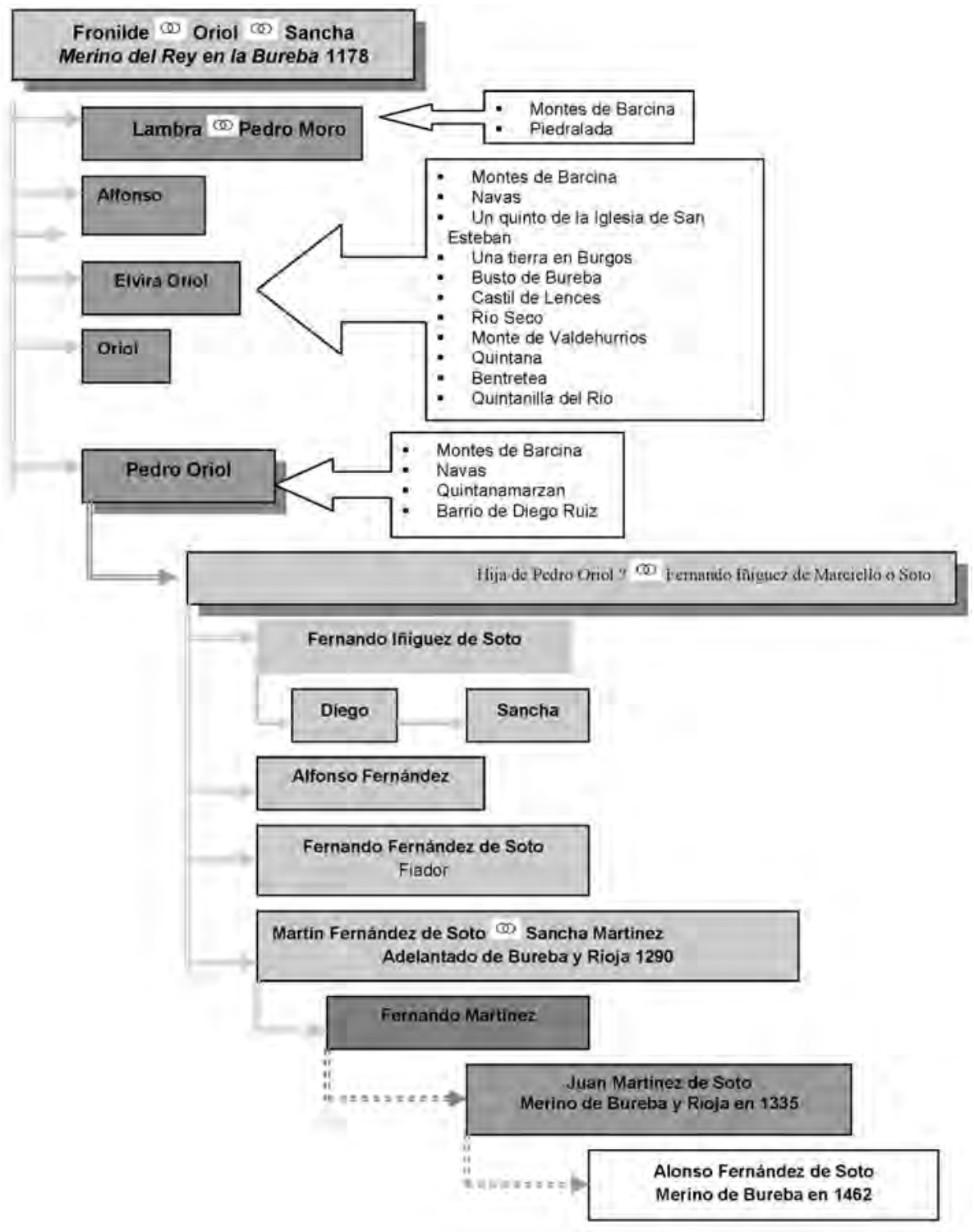

Genealogía y propiedades de los Oriol. S.S. XIII y XIV. 
vios de los merinos del Merino Mayor de Castilla, García Fernández de Villamayor, que lo fue desde 1302 a 1304, a los vecinos de Miranda ${ }^{94}$.

El 28 de diciembre de 1301 se presentaba ante el Merino Mayor y ante otros testigos entre los que se encontraba Pedro Díaz de Río Cerezo, merino de Bureba y Rioja, un escrito de querellas que tenían los vecinos de Miranda a causa de los desmanes que diversos personajes, incluidos algunos merinos, habían cometido. Desde hacía unos años habían sustraído de los habitantes de la zona un buen número de ganado y diferentes enseres, que en el relato de las quereIlas aparecen detalladamente valorados por los vecinos.

Entre estos personajes se encontraba Martín Sánchez y que pudiera ser el mismo que posteriormente aparecerá como Merino de Bureba y Rioja, el que en octubre de 1298 acompañado por Juan Martínez de Rojas, Ilevaron diversos animales por mandado de don Juan Alfonso en razón de la fonsadera. El concejo les mostró el privilegio del rey de que no debían fonsadera y una carta del rey Fernando en la que decía que a los de Miranda no debían demandarles nada a cambio de la fonsadera. Ni don Juan Alfonso, ni Martín Sánchez, ni Juan Martínez, hicieron caso del privilegio concejil.

En octubre de 1301, Martín Sánchez, ya denominado Merino de Bureba y Rioja, tomó algunos animales por valor de 200 maravedíes diciendo que lo llevaba por "omeziellos" de los dos escuderos que murieron cuando Juan Martínez y sus hermanos y su compaña mataron a Diego Pérez, el alcalde. Ante esta actuación el concejo le mandó decir que "omme ffiyo dalgo dalaua non auia omezillo et que nos mandasse DCC nuestras pendras et desy quando demandasse alos mercadores ssy nuestros uezinos fuesen queles ffariamos ffazer cumplimiento de fuero et de derecho et ssy enessa razón o en otra del conceyo ouiessen querella que les dariamos ffiadores de conplir quanto el rrey mandasse o el fuero E desto nos quisieron ffazer ninguna cosa nin dar nos la enpendra". El concejo reclamaba lo que se le debía por la actuación del merino.

En noviembre de ese mismo año los hombres del mismo merino y los porteros de Pancorbo tomaron de Martín Pérez de Cellorigo, 13 fanegas de trigo, 2 de harina, 3 de habas y de yeros y diversas prendas por valor de 500 maravedíes, Ilevando también a su mujer presa, por fianza que era el dicho Martín Pérez de don Mateo de Cellorigo en contra de un judío de Pancorbo. El concejo mostró a Martín Sánchez los privilegios y las cartas del rey de no "merinar" en Miranda ni en sus aldeas, sin embargo, el merino no los quiso recibir y se llevó a la mujer y a otros presos en la cadena, a Briviesca.

No obstante, consideramos que debemos puntualizar estas actuaciones. Si en 1299 hemos visto las quejas del concejo calceatense por los "entramientos"

94. CANTERA, F. y ANDRíO, J., Historia Medieval de Miranda..., doc. 61. 
de ciertos caballeros, las quejas del concejo de Miranda hemos de verlas como un conflicto de intereses, aprovechando el tiempo de inestabilidad política que supuso la regencia y minoría de edad del rey, lo que supondría una buena forma de sacudirse el yugo impositivo real. No debemos olvidar que la regente María de Molina tuvo que buscar apoyos políticos en los concejos para poder, de este modo, enfrentarse a la levantisca nobleza.

En el extenso documento también nos aparece lo que podríamos calificar, en este caso, como conflictos de intereses territoriales. De entre los hechos relatados destacamos los habidos con los vecinos de Cellorigo por el cobro de impuestos por parte de los "cogedores de servicios" de la Merindad de Bureba y Rioja. En 1297 se llevaron diversos ganados, mientras los de Cellorigo, que pechaban con los de Miranda, ya habían pagado a los "cogedores" de la merindad de Castilla-Vieja.

En noviembre de 1299 volvieron a llevarse diversos ganados por el pago de los servicios que el rey había impuesto a las aldeas de realengo pero los de Cellorigo volvieron a decir que lo habían pechado a los "cogedores" de CastiIla-Vieja. En mayo de 1301, los vecinos de Cellorigo volvieron a mostrar a los "cogedores" de Bureba y Rioja, las cartas del rey Fernando en las que se decía que debían pechar a los "cogedores" de Castilla-Vieja, pero no reconociendo estas cartas, los de "Rioja" les tomaron mil cuarenta maravedíes y una "bestia que se perdió" y que valía cien maravedíes.

Y las quejas por los agravios se siguen produciendo. El 15 de enero de 1302, se acusa a Ramiro García de Bañuelos, Merino en Bureba y Rioja, que en agosto había tomado en Orón algunos animales, diciendo que los tomaba porque en Miranda no consentían que merinase, ni recoger las entregas de los judíos y como no le valió el fiador que el fuero les permitía, tuvieron que redimir el ganado con Gonzalo García por 700 maravedíes y en daños en las labores, por mas de 600 maravedíes.

En octubre de 1303 vuelven los vecinos de Miranda a presentar quejas de los merinos de don García Fernández (de Villamayor), Adelantado Mayor de Castilla. La protesta va dirigida contra Pedro Díaz de Río Cerezo, el mismo merino de Bureba y Rioja que dos años antes había sido testigo de las protestas de los mismos vecinos mirandeses. Sin embargo, en este caso no es por el cobro de impuestos, sino por ejecutar la justicia del rey en cuestión de delitos. Se trataba de la puesta en prisión de Martín Pérez de Cellorigo y de su mujer, acusándolos de que el capirote que traía en la cabeza un hijo suyo de un año se asemejaba al manto que perdió la nieta de don Pedro de Ameyugo que era la barragana ${ }^{95}$ del merino. Les condenó a siete días en la cadena, no admitiendo

95. Según las Partidas a los merinos les estaba prohibido tomar por esposa a ninguna mujer en el territorio donde ejercían su jurisdicción durante el tiempo que ejercían el cargo. No obstante en "Partidas, IV, 14, 2" se precisa: "E podria y rescibir barragana, si non ouiesse muger legitima". 
fiadores según manda el fuero, poniéndoles un mediador para que se arrepintiesen y no pagaran la infurción. Se les perdonó por un yantar para el merino de 129 maravedíes, saliendo fiadores los parientes de Martín Pérez de una fianza de 140 maravedíes.

Todos estos hechos reseñados nos indican que el concejo de Miranda está pidiendo que se reconozca la validez a los privilegios recibidos desde la época de Fernando III. Resulta significativa la ausencia de Alfonso X y Sancho IV a los que se considera responsables del excesivo poder de la nobleza. No obstante cabe preguntarse, ¿las actuaciones de los merinos exceden sus ámbitos de competencias?. De lo expuesto se deduce que Orón y Cellorigo pertenecen a la Merindad de Castilla-Vieja pero en zona limítrofe con la Merindad de Bureba y Rioja; también hacemos notar la ausencia de los merinos de Castilla-Vieja, o ¿es qué ante esta ausencia, los merinos de la merindad vecina y en cumplimiento de sus funciones, asumen la autoridad para los cobros de las rentas del rey?. En esta situación no queda constancia si los pecheros pagaron o se evadieron con la excusa de haber pagado a sus propios merinos. De lo que si queda constancia y detalladamente valorado por todos los vecinos querellantes es de lo enajenado por los merinos.

Ante estos hechos presentados nos volvemos a preguntar, ¿los vecinos de los concejos, se estaban aprovechando de la coyuntura socio-política del reino y de este modo no pagar impuestos?, ¿era aprovechada la inestabilidad política por los concejos para no obedecer la justicia del rey?

No obstante, las quejas de los mirandeses hicieron su efecto pues el 25 de agosto de 1304, el rey Fernando mandó una carta a Lope Fernández de Santo Domingo, cogedor de los servicios de Bureba y Rioja para que los vecinos de Cellorigo fuesen quitados del padrón de la merindad de Bureba y Rioja y pechasen éstos en el concejo de Miranda ${ }^{96}$. De este modo, Cellorigo, pasaría a formar parte de la Merindad de Castilla Vieja.

Durante los años siguientes las quejas se siguen sucediendo. Los impuestos extraordinarios se añadían a los ordinarios porque éstos no bastaban para pagar las soldadas de los infantes, ricos-hombres y caballeros, que habían absorbido en los siete años de la minoría del rey nada menos que quince servicios extraordinarios, equivalente cada uno aproximadamente al diez por ciento de los bienes de los contribuyentes: campesinos y ciudadanos, pues clérigos y nobles están exentos. Esta sangría fiscal, la mala administración, la impotencia de la justicia para reprimir los abusos de los nobles y de los oficiales del rey, no serán oídas hasta que en 1312 en un intento de sustituirle por parte de su hermano Pedro, se vea obligado Fernando IV a recurrir a los concejos y a los eclesiásticos. Su respuesta a dichas quejas se refleja en la carta que envía a los monas-

96. CANTERA, F. y ANDRÍO, J., Historia Medieval de Miranda..., doc. 68. 
terios de Castilla, mandando que ningún monasterio, sea de la Orden que sea, pague nada por razón de entrada. La causa de su pobreza era provocada especialmente por las entradas de adelantados y merinos ${ }^{97}$.

Este mismo año moría Fernando IV y el reino entraba en una nueva minoría, más agitada aún que la anterior.

El nuevo reinado se presentaba con un perfil semejante a los anteriores. Nacido tan sólo un año antes en Salamanca, en 1312 a Alfonso XI le correspondió suceder a su padre en el trono.

Durante este período, la documentación consultada no nos ofrece el nombre de ningún merino, tan solo encontramos misivas enviadas al Merino Mayor de Castilla y a los "merinos que anduvieren" por nuestra merindad en respuesta a las quejas presentadas por señoríos y concejos.

El primer documento que nos encontramos para este reinado es la carta que envía el rey el 18 de junio de 1314 al concejo de Santo Domingo de la Calzada eximiendo de ciertos pechos y reduciendo a ochenta el número de pecheros que debían ponerse en cabeza del concejo para frenar el despoblamiento. El concejo se había quejado al rey y al infante Juan, señor de Vizcaya y tutor, de los robos que habían hecho ciertos caballeros sobre las tierras. De los ciento quince pecheros que tenía el concejo manda que quiten treinta y cinco de los padrones de la Merindad de Bureba y Rioja ${ }^{98}$. Dos años más tarde, el rey vuelve a confirmar la misma orden.

En 1315 concede a Lope Fernández de Calzada una dehesa acotada en Val de San Miguel en el término de Bañuelos (hoy despoblado) ${ }^{99}$. La concesión es dada en igualdad de derechos a las dehesas acotadas que los concejos de Camprovin, Baños y Ledesma que "son en tierra de Nájera en la merindat de Rioja". Este es el mismo personaje que en el reinado anterior era el cogedor de los servicios en nuestra merindad, además, el límite oriental de la merindad seguía estando en la cuenca del río Najerilla.

En este período de inestabilidad política vemos como el rey y sus tutores, cediendo ante las presiones, en este caso del monasterio de Vileña, ordena en abril de 1317, a su Merino Mayor, García Laso de la Vega y los merinos que anduvieren en la Merindad de Bureba y Rioja que los vecinos de la Vid, vasallos del monasterio, no paguen tributos al rey sino a la abadesa. Lo mismo sucede con un vasallo de Poza para que sea quitado del padrón de la merindad $^{100}$.

97. CANTERA MONTENEGRO, M., Santa María La Real de Nájera, SS. XI-XIV, Tesis Doctoral inédita. Universidad Complutense de Madrid, 1987, vols. 2 y 3, doc. 229. doc. 16 .

98. LÓPEZ DE SILANES, C. y SÁINZ RIPA, E., Col. Diplom. Calceatense. Arch. Munic.,

99. COLECCIÓN HERGUETA, T. 4, s. nº, s. f.

100. CADIÑANOS BARDECI, I., Cartulario de Vileña, docs. CLXV y CLXVI. 
Una muestra de estos tiempos de crisis la vemos reflejada en las sucesivas quejas que recibe el rey por parte de los poderes señoriales y concejiles. En Burgos, el 15 de mayo de 1326 el abad de San Millán se queja de que los lugares de Badarán, Villagonzalo, Terrero y Villolquit, "eran yermos et se despoblaban por muchas fuerzas et daños et males, que les hacian de cada dia los fijosdalgo de la comarca...". El rey ordena a los merinos que anduvieran en la Merindad que formen un solo padrón con los pechos y derechos en cabeza de Badarán junto con los otros tres lugares. En otro documento y en la misma fecha y también por la queja del abad de San Millán, ordena a los merinos que protejan a los vasallos del monasterio y no se embarguen sus bienes ${ }^{101}$.

También el monasterio de Vileña le reclama privilegios anteriormente concedidos sobre los pobladores de la Vid, vasallos del monasterio, no paguen los tributos reales. Por esto el rey ordena a los cogedores de los servicios y moneda que los quiten del padrón de la Merindad ${ }^{102}$.

En 1326 el concejo de Santo Domingo de la Calzada vuelve a presentar quejas ante el rey, esta vez por los agravios que habían hecho a la ciudad los merinos mayores de Castilla. El rey prohíbe a los merinos de la Merindad de Rioja que entren a hacer justicia en la villa ni a cobrar el yantar, también les ordena que defiendan al concejo y que cuando tengan que hacer justicia la hagan después del rey, de los alcaldes o del merino de Santo Domingo, según fuero. El mismo documento presenta confirmación de los derechos en los años de 1333 y $1371^{103}$.

En 1328 el rey atiende la petición del concejo de Miranda de que la aldea de Villalba sea puesta en cabeza del dicho concejo. La carta la dirige a los que están haciendo los padrones en la Merindad de Bureba y Rioja ${ }^{104}$. Un año más tarde son los vecinos de Villaseca los que piden al rey ser vasallos suyos y vecinos de Miranda a causa de la destrucción de sus tierras y cosechas por "omes poderosos"105. Seguían sucediéndose las "malfetrías" y en consecuencia, sangría de las rentas del reino y miseria sobre los oprimidos campesinos.

En 1329 en su viaje a Aragón donde casará a su hermana la infanta Leonor con Alfonso el Benigno, se detiene en el monasterio de San Millán y atiende la petición del abad de eximir de impuestos (pechos, pedidos, fonsado, fonsadera, servicios, martiniega, marzadga, yantar, acémilas, excepto la moneda forera) a sus vasallos de Pazuengos, Madriz, Santurdi, Villaverde, Badarán y Cárdenas, durante diez años, a causa de: "...robos et daños et males que disen que an

101. COLECCIÓN HERGUETA, T. 4, s. no s. f.

102. CADIÑANOS BARDECI, I., Cartulario de Vileña, doc. CLXXVI.

103. SILANES - RIPA, Col. Diplo. Calc. Arch. Municipal, doc. 19.

104. CANTERA, Doc. H. M. Miranda, doc. 75.

105. CANTERA, Doc. H. M. Miranda, doc. 76. 
recebido ellos et los sus vasallos e los sus logares de ricos onmes et de infanzones et caballeros... que andaban por esa tierra." ${ }^{\prime 06}$.

El monasterio de Cañas también reclama al rey. Ese mismo año dirige cartas al merino de la Merindad de Bureba y Rioja eximiendo a los vasallos del monasterio y a los vecinos de Valluércanes, vasallos también del monasterio, del pago de la fonsadera; y la concesión al dicho monasterio de los pagos que habían de dar al rey durante cien años los cien pecheros de Quintanilla de San García ${ }^{107}$.

Por todo lo expuesto estamos viendo como rentas regias y derechos jurisdiccionales pasan a manos de los señores y concejos. Según Álvarez Borge, "este cambio es posible gracias a que el poder regio adquiere nuevos contenidos, pero también provoca y posibilita la formación de esos nuevos contenidos del poder regio" y se resume en dos aspectos fundamentales: "...la superioridad jurisdiccional del rey... y, en la organización de la fiscalidad regia..."108. Relación causa-efecto.

También hay que tener en cuenta que habían sobrevivido los derechos forales, con toda su diversidad y casuística intrínsecas, y que, fuera de la corte, las justicias regias habían encontrado serias dificultades para penetrar en los concejos hasta el final del reinado.

Durante este tiempo en la documentación consultada no nos aparece el nombre de ningún merino. Los ordenamientos reales sólo hacen referencia a la territorialidad de Bureba y Rioja como este de 1330, en el que el rey Alfonso XI manda el "merino que anduviera en la merindad de Bureba y Rioja", que la décima parte del portazgo de Pancorbo sea entregado al monasterio de Oña ${ }^{109}$ y también en 1332 eximiendo al monasterio de San Millán del vaso y la mula que daban al merino mayor; la carta está dirigida al Merino Mayor de Castilla y a los merinos que anduvieren por él en la Merindad de Bureba y Rioja ${ }^{110}$.

Es en 1331 cuando aparece Diego Ortiz Calderón Merino del Rey en Rioja, actuando de testigo en el pleito entre el cabildo y la ciudad de Santo Domingo por el cual se acuerda que debía pagar esta ciudad 750 maravedíes al cabildo en razón de la marzadga'11. Cuatro años mas tarde, en abril de 1335, es Fernán González de Herramélluri Merino del Rey de la Merindad de Rioja, por Juan Martínez de Leiva Adelantado Mayor en Castilla, quien a petición de la abadesa de Cañas embarga los bienes de Ayuela ${ }^{112}$. Los vecinos de este lugar, perte-

106. COLECCIÓN HERGUETA, T. 4, s. $n^{\circ}$, s. f.

107. JIMÉNEZ MARTINEZ, C., Santa María de Cañas, Tesis de Licenciatura. Universidad de Zaragoza, 1986, docs. 107, 108, 112.

108. ÁLVAREZ BORGE, I., Monarquía feudal..., p. 186.

109. OCEJA, Oña, doc. 627.

110. COLECCIÓN HERGUETA, s. no , s. f. Códice Minguella, doc. 648.

111. SILANES - RIPA, Col. Diplo. Calc. Arch. Catedral, doc. 82.

112. JIMÉNEZ, C., Sta . María de Cañas, doc. 120. 
neciente al monasterio, lo habían abandonado y se habían ido a vivir a Santo Domingo, sin embargo, éstos volvían al lugar a labrar viñas y tierras y a cortar los montes. El monasterio puso el pleito en manos del merino, prohibiendo éste la entrada a la villa de los vecinos.

La titulación del merino "solo" de Rioja nos pudiera hacer sospechar que la merindad pudiera estar dividida en dos circunscripciones pero un documento de 1 de septiembre de 1335 nos aclara esa titulación. Se trata de la venta de unos bienes al concejo de Santo Domingo de la Calzada, realizados por Juan López de Mendoza, Merino de la Merindad de Rioja, y que el alcalde calceatense tenía embargados. Este nuevo nombramiento pudiera estar causado por el nuevo Merino Mayor de Castilla. Estos bienes embargados eran el resultado de una querella que se presentó ante Ferran Pérez Portocarrero, Merino Mayor de Castilla y ante García Martínez de Miranda, alcalde del rey, y que su resolución se notificó en una carta que éste envió a Juan Martínez de Soto Merino en la Merindad de Bureba y Rioja "o otro cualquier meryno que anduviere (...) en la dicha meryndat e en tierra de Rrioia salud..." ${ }^{\prime 13}$. El Merino de Rioja se ha convertido en este tiempo en un cargo subsidiario de la entidad superior que es la Merindad de Bureba y Rioja. Un dato que no queremos dejar pasar es que el merino sea Martínez de Soto, quien suponemos que sea descendiente de Fernández de Soto, Merino de Bureba y Rioja en 1290.

Recordaremos que a petición del concejo de Santo Domingo en 1326, el rey concedió privilegio de inmunidad de entrada de merinos, debido a las quejas por daños y agravios que causaban sus intervenciones. Lo mismo había sucedido cuatro años antes en Belorado. En 1322 Alfonso XI manda que ningún merino mayor ni adelantado mayor de Castilla entre en Belorado y sus aldeas a cobrar tributo alguno ni se atrevan a prender, matar ni demandar cosa alguna que sea debida por razón de merindad"14. Goicolea plantea que: "Se trataba, en definitiva, de favorecer al poder concejil, pero interviniendo al mismo tiempo en los asuntos municipales a través de otras fórmulas, de ahí las referencias a alcaldes del rey que documentamos a partir de inicios de la década de los años treinta del siglo XIV en Logroño, Santo Domingo de la Calzada y Calahorra"115 Las villas siguieron siendo centros de poder importante durante todo el siglo XIV y su gobierno municipal constituía para los habitantes el referente más cercano y directo, tal es el caso del concejo de Santo Domingo. Los territorios bajo jurisdicción de las villas configuraban una gran parte del conjunto de la región, por lo tanto, hay que tener en cuenta que no sólo se trataba del núcleo urbano en

113. SILANES - RIPA, Col. Diplo. Calc. Arch. Municipal, doc. 26.

114. BLANCO GARCÍA, F., "Catalogación de Documentos Medievales de la Rioja Burgalesa", en Boletín Fernán González, 1971, nº 177, doc. 19.

115. GOICOLEA, F.J., El gobierno urbano en La Rioja en época Medieval e inicios de la Edad Moderna, Logroño, 2004, pp. 24, 25. 
sí, sino de la "tierra" o ámbito jurisdiccional que dependía del concejo cabecero. Y en consecuencia esto se vería manifestado dentro de la merindad en la formación de una jurisdicción específica para Rioja. En lo que concierne a Belorado veremos como unos años mas tarde aparece una nueva reorganización territorial. En 1332 Alfonso XI toma bajo su protección al monasterio de Santa María de Linares, cercano a Belorado. La carta la dirige a los merinos de las merindades de Bureba, de Rioja y de Montes de Oca. ${ }^{116}$ Esto representa la secesión del territorio bajo la influencia que ejercen los concejos. Quizás y de este modo, como plantea Goicolea Julián "se daba una respuesta positiva a las demandas de mayor autonomía del poder concejil117. Lo que explica esta nueva reorganización del territorio.

Sin embargo esto no parece que se de en otras partes de la Merindad como puede verse en las actuaciones del merino en el señorío del monasterio de Oña. En septiembre de 1338 vemos al Merino del Rey en la Merindad de Bureba y Rioja, Ferrando Díaz de Ovirna (Ubierna) acotando y deslindado los montes y dehesas del monasterio de Oña ${ }^{118}$. El 7 de septiembre del mismo año Fernando Pérez de Portocarrero, Adelantado Mayor de Castilla recuerda a los merinos la obligación que tienen de proteger los privilegios del monasterio respecto de sus montes ríos y piélagos ${ }^{119}$.

Ese mismo año, el Adelantado en Rioja es Martín Pérez de Redecilla, lo vemos eximiendo de todo impuesto al lugar de Ajuarte por estar yermo y despoblado ${ }^{120}$. Aparte de su significación política, este documento resulta muy ilustrativo para mostrarnos la existencia de una crisis generalizada con secuelas socioeconómicas desastrosas, que incidió en todas las estructuras del Medievo. Resulta significativo que dos años antes dos canónigos de Santo Domingo de La Calzada visitaron las posesiones de ese mismo lugar, levantando un apeo de sus posesiones, viñas y piezas ${ }^{121}$.

En noviembre de 1338, el rey Alfonso XI, envía una carta al Merino Mayor de Castilla y por él al Merino de Bureba y Rioja y Tierra de Nájera para que los vecinos de Briones pudieran llevar sus ganados y cortar leña en el término de La Verde, en Nájera ${ }^{122}$. El concejo de Briones, vasallo de don Fadrique, hijo del rey, se había querellado porque el concejo de Nájera y alguno de sus vecinos les habían embargado los ganados, no dejándolos entrar en el término.

116. SILANES-RIPA, Col. Dip. Cal. Arch. Cat. doc. 84.

117. GOICOLEA, F.J., El Gobierno urbano... p. 24.

118. OCEJA, Oña, doc. 671.

119. OCEJA, Oña, doc. 670.

120. SILANES - RIPA, Col. Diplo. Calc. Arch. Catedral, doc. 92.

121. SILANES - RIPA, Col. Diplo. Calc. Arch. Catedral, doc. 90.

122. COlECCIÓN HERGUETA, T.4,S. No ${ }^{\circ}$ S. F.Acad. Hist. Colec. Conde de Mora.Tomo IV, p. 304. 
Para febrero de 1339 se había nombrado a otro merino, Juan Pérez de Valluércanes que por orden del Adelantado Mayor de Castilla y a petición del abad de Oña, acota los montes y dehesas de la abadía ${ }^{123}$. Consideramos que este personaje pudiera estar en relación con Martín Pérez de Valluércanes, jurado y testigo en un requerimiento que hace el concejo de Santo Domingo en $1332^{124}$. El cargo de jurado era "un oficial del concejo dotado de poder político"125.

En 1341 aparece un merino, Juan González de Celada en un pleito entre el monasterio de Cañas y el concejo de Santo Domingo por el lugar de Ayuela ${ }^{126}$. En 1343 el mismo merino Ilevaba a cabo una pesquisa en La Vid y Berzosa para el monasterio de Vileña ${ }^{127}$. Al actuar en lugares de nuestra merindad hemos considerado que pudiera tener alguna relación de cargo y lo hemos añadido a la lista de oficiales, pero con ciertas reservas debido a la poca información que nos ofrecen los documentos consultados. No obstante, en diciembre de 1342 era Juan Ochoa de Zancada merino en la Merindad de Bureba y Rioja ${ }^{128}$, por lo que también cabría la posibilidad que fuese merino al servicio del monasterio de Vileña.

Tres años mas tarde, en 1345, volvemos a ver cambios en nuestra merindad. En una donación al monasterio de Oña, actúa de testigo Juan Pérez de Valluércanes Merino del rey en la Merindad de Bureba, el mismo personaje que seis años antes era Merino en Bureba y Rioja. No sabemos que le llevó a ocupar el cargo en la Bureba pero en el mismo documento podemos observar como el territorio de nuestra merindad se había separado: "...damos poder por esta carta e pedimos al merino mayor de Castilla e a qalquier merino o merinos que por el andudieren en las merindades de Burueua e de Rioia..." ${ }^{\prime 29}$.

No podemos precisar una causa para esta nueva separación, no obstante, al ser un territorio perteneciente a la administración real, quizá podría reflejarse en él los cambios institucionales que se llevaron a cabo en el reinado de Alfonso XI, como el refuerzo de la hacienda regia con una fiscalidad más desarrollada. Esto nos lleva a suponer el hecho de configurar un territorio hacendístico más concreto y controlable. La división de un territorio que si bien pudiera ser homogéneo en sus comienzos, bien comunicado por antiguas vías romanas y posteriormente por el Camino de Santiago, ahora se presenta más heterogéneo debido a la confluencia en él de diversos intereses, señoriales y concejiles.

123. OCEJA, Oña, doc. 675.

124. SILANES - RIPA, Col. Diplo. Calc. Arch. Municipal, doc. 21.

125. GOICOLEA JULIÁN, F.J., El gobierno urbano..., p. 19.

126. JIMENEZ, Cañas, doc. 126.

127. CADIÑANOS, Vileña, doc. 192.

128. SILANES - RIPA, Col. Dipl. Calce. Arch. Catedral, doc. 94.

129. OCEJA, Oña, doc. 704. 
Pedro I le sucedió en 1350. Un año mas tarde presidiría Cortes en Valladolid para tratar de salir al paso de los desastres económico-sociales causados por la peste, y atender las reclamaciones presentadas por los concejos.

El 15 de octubre, el rey dio respuesta a las reclamaciones del concejo de Miranda y envió una carta a los que tenían el padrón de la Merindad de Bureba y Rioja para que borraran a los 36 pecheros de Galbárruri y a los 5 pecheros de Villalba y ponerlos en cabeza de la Merindad de Castilla-Vieja ${ }^{130}$. Al ser una reclamación hecha en 1328 ante Alfonso XI la denominación formal de la Merindad era la que estaba formada a principios de su reinado porque como hemos visto hacia su final, la Merindad forma dos unidades administrativas independientes.

En las Cortes le fueron presentados al rey, por los procuradores de Belorado, la queja del mal estado del puente sobre el río Tirón. En el documento se dice que la reparación del citado puente se reparta entre las Merindades de Rioja y la Bureba ${ }^{131}$. Resulta muy ilustrativa la información que nos proporciona, en cuanto a que nos dice donde queda establecida la "frontera", en este caso natural, que proporciona el río Tirón entre las dos merindades. En otro documento fechado en noviembre, se concede el privilegio a la villa de Belorado de recaudar el dinero cobrado a todos los que pasasen por el puente pero solamente el suficiente para su reparación ${ }^{132}$.

También en estas Cortes se trataron de los enfrentamientos habidos entre los grupos nobiliarios a causa de los lugares de behetría con la petición de su reparto con carácter perpetuo, renunciando asimismo el monarca a la administración de justicia en dichos lugares, es decir, su conversión en "solariegos".

Pedro I ordenó que una comisión de prelados, caballeros y hombres de las villas realizara un inventario de los lugares de behetría, especificando en cada caso quiénes tenían derecho sobre ellos y cuáles eran éstos, pero se negó a ceder la administración de justicia y la parte de impuestos que le correspondía.

Se formó una comisión que redactó un verdadero "índice fiscal" en el que figuran lugares con la mención de sus señores, de los tributos pagados por los campesinos y de los beneficiarios (esta es la parte conservada). Estos documentos habrían permitido al rey conocer con todo detalle las cantidades que percibían los señores, las que correspondían al monarca y, lo que es más importante, averiguar la autenticidad o falsedad de los derechos nobiliarios.

El resultado fue el Ilamado "Libro Becerro de las Merindades de Castilla", conocido como "Becerro de las Behetrías", que aporta entre otras muchas

130. CANTERA, Doc. Hist. Medie. Miranda, doc. 113.

131. COLECCIÓN HERGUETA, T.4, s.nº, s.f.

132. BLANCO GARCÍA, F., "Catalogación de documentos medievales de la Rioja Burgalesa", en Boletín Fernán González, nº 177. Madrid 1973, doc. 21. 
cosas, una descripción prácticamente completa de la organización territorial de Castilla al norte del Duero. El control del gobierno de estos territorios se hace por medio de oficiales de nombramiento real.

La Merindad Mayor de Castilla estaba formada por diecinueve merindades menores, pero solo han Ilegado hasta nosotros información sobre quince de las formadas. No obstante, si el "Becerro" no nos legó la "imagen" geográfica ni documental de la merindad objeto de nuestro estudio, casi podemos asegurar que, si fue descrita en él, sería presentada como dos unidades administrativas diferenciadas, tal como la veíamos al final del reinado de Alfonso XI y de la misma manera que podemos observar en la documentación consultada con posterioridad a la redacción del libro. Desde este momento la Merindad de Bureba y Rioja, que desde comienzos del S. XIII vemos configurarse como una unidad administrativa, con algunos intervalos de separación, ya no formará esa misma unidad. La Bureba, de la que tenemos para esta época escasa documentación, seguirá configurándose como, un territorio con muy marcado carácter geográfico y con unos dominios monásticos muy influyentes: Oña, Huelgas, Vileña. No ocurrirá lo mismo con el territorio riojano, marcado por una geografía más heterogénea e influenciada por un nuevo poder emergente desde finales del S. XIII, los concejos; con autonomía, territorio jurisdiccional y estatuto jurídico y que permanecen bajo el realengo en cuyas tierras se habían formado ${ }^{133}$.

Serán los concejos, ejerciendo una atracción centrífuga, los que van a configurar, a partir de este momento, el territorio de la Merindad de Rioja. Ya hemos tenido ocasión de observar como el concejo de Miranda, ejercía su influencia en los lugares riojanos de Galvárruli, Cellorigo, Villaseca, Villalva, pasando a formar parte de la Merindad de Castilla-Vieja.

Durante este reinado no nos aparecerá el nombre de ningún merino, sin embargo, en un documento de 1354 encontramos a varios merinos menores haciendo referencia a su oficio anterior. Se trata de una reclamación presentada por el abad de Oña al rey Pedro I sobre ciertos privilegios de exención que poseía el monasterio y sus vasallos, por las prendas que tomaban los merinos en su ejercicio, mula, vaso, yantar y entrada ${ }^{134}$. La orden se establece con carácter retroactivo a que devuelvan las prendas tomadas, dirigiéndose a los merinos que estuvieron en tiempos de Ferrán Pérez Portocarrero, Merino Mayor de Castilla desde 1334 a 1350 y en $1353^{135}$ figurando entre ellos figura Avar Díaz de Sotiello, "merino que fuestes de la merindad de Burueva e de Rioja". Bien se

133. GOICOLEA, F.J., "La expansión territorial de los núcleos urbanos y la articulación de las relaciones con sus aldeas en la Rioja Alta Medieval", en Anuario de Estudios Medievales n 32. 2002, pp 293-330.

134. RUIZ GÓMEZ, F., Las formas de poblamiento rural en la Bureba en la Baja Edad Media: la villa de Oña, Madrid, 1988, Tomo II, doc. 88.

135. ÁLVAREZ BORGE, I., Monarquía feudal..., Cuadro III, p. 214. 
puede deducir que este merino estuvo bajo el reinado de Alfonso XI, sin embargo, para este tiempo, la documentación solo nos ofrece la denominación territorial administrativa.

En 1355, el rey Pedro I dona a Iñigo Ortiz de Zúñiga el lugar de Azofra, villa de realengo y situada en la Merindad de Rioja ${ }^{136}$. Una generosa compensación para atraer a su causa en la lucha armada que iba a presentar a su hermanastro el bastardo Enrique de Trastámara.

Un ejemplo del poder concejil lo tenemos en la carta de hermandad y concordia que, en 1358, firman los concejos de Santo Domingo y Bañares. En ella se da poder al merino en la Merindad de Rioja para que infrinja penas pecuniarias al concejo que no cumpla con el compromiso ${ }^{137}$. Se ha hecho, en este caso, un trasvase de poder del Rey hacia los concejos.

136. COLECCIÓN HERGUETA, T. 4, s. nº, s. f.

137. SILANES - RIPA, Col. Diplm. Calc. Arch. Municipal, doc. 33: "E por mayor firmeza damos poder e autoridat por esta carta a qualquier merino del Riey que fuere por tiempo en la merindat de Rioja que prende e tome tambien de los bienes del conceio que non guardare e tosiere esta dicha hermandad...". 


\section{Cuadro I. Tenentes y merinos: S.S. XI-XII}

\begin{tabular}{|c|c|c|c|}
\hline Fecha & Nombre & Titulación & Fuente \\
\hline 1040 & García Oriol & Señor de Briviesca & LAMA, CDMR, T.II, doc. 3 \\
\hline 1061 & Flaíno Oriol & Merino en Bureba & SERRANO, S.M, docs. 167, 177 \\
\hline 1089 & $\begin{array}{l}\text { Condesa Sancha viuda de } \\
\text { Gonzalo Salvadores }\end{array}$ & Tenente en Bureba & ALAMO, Oña, doc. 95 \\
\hline \begin{tabular}{|l|}
$1102-$ \\
1106 \\
\end{tabular} & Conde Gómez & Tenente en Bureba & ALAMO, Oña, docs.115, 124 \\
\hline 1106 & Conde Gómez & $\begin{array}{l}\text { Tenente en Cerezo, Pancorbo, } \\
\text { Piedralada }\end{array}$ & $\begin{array}{l}\text { LEDESMA, San Millán, } \\
\text { doc. } 313\end{array}$ \\
\hline 1107 & Conde Gómez & Tenente en Bureba & LEDESMA, San Millán, doc. 5 \\
\hline 1076 & Martín Sánchez & Tenente en Nájera & GARCÍA TURZA, Valva, doc. 84 \\
\hline 1081 & Pedro lbáñez & Tenente en Nájera & LAMA, CDMR T. II, doc. 37 \\
\hline 1077 & Martín Sánchez & Merino en Burgos y en Cerezo & LEDESMA, San Millán, docs. 4, 8 \\
\hline $1077 ?$ & Fortún Manso & Merino del Rey & LEDESMA, San Millán, doc. 8 \\
\hline 1089 & Pedro Ibáñez & Merino del Rey & LEDESMA, San Millán, doc. 189 \\
\hline $1128-1130$ & Lope Iñiguez & Tenente en Bureba y Alfaro & LAMA. CDMR, T. II, doc, 98 \\
\hline 1131 & Rodrigo Gómez & Tenente en Bureba & OCEJA, Oña, doc. 49 \\
\hline 1152 & Gonzalo Ruiz & Tenente en Bureba & LEDESMA, San Millán, doc. 391 \\
\hline 1152 & Alfonso Muñoz & Merino del Emperador & LEDESMA, San Millán, doc. 391 \\
\hline 1155 & Pedro Fortuñones de Royuela. & Adelantado del Rey & LEDESMA, San Millán, doc. 395 \\
\hline 1156 & Gonzalo Rodríguez & Tenente en Bureba & ALAMO, Oña, doc. 222 \\
\hline 1156 & Fernando Ibáñez & Merino & ALAMO, Oña, doc. 222 \\
\hline 1170 & Gonzalo Rodríguez & Tenente en Bureba & LEDESMA, San Millán, doc. 413 \\
\hline 1170 & Oriol & Merino & LEDESMA, San Millán, doc. 413 \\
\hline 1178 & Oriol & Merino mayor en Bureba & GONZÁLEZ, Alf VIII, T. III, doc. 294 \\
\hline 1178 & Pedro, Germanus & Merino en Bureba & GONZÁLEZ, Alf VIII, T. III, doc. 294 \\
\hline 1181 & Martín de la Follía & Merino en Bureba & ALAMO, Oña, doc. 252 \\
\hline 1183 & $\begin{array}{l}\text { Pedro García de Lerma } \\
\text { Fortún García de Ayuela }\end{array}$ & $\begin{array}{l}\text { Tenente en Grañón y en Rioja } \\
\text { Merino }\end{array}$ & $\begin{array}{l}\text { UBIETO, Doc. St'D.Calzada, } \\
\text { doc. } 61\end{array}$ \\
\hline 1185 & Borreco & Merino del Rey & LEDESMA, San Millán, doc. 447 \\
\hline 1186 & Oriol & Merino del Rey & LEDESMA, San Millán, doc. 449 \\
\hline 1191 & Lupus Moggo & Merino en Rioja & LEDESMA, S. M, docs. 464, 465 \\
\hline 1193 & Don lague & Merino del Rey en Bureba & ALAMO, Oña, doc. 305 \\
\hline 1207 & Diego Martínez & Adelantado del Rey & UBIETO, Col. St ${ }^{\circ}$ D. C., doc. 92 \\
\hline 1211 & Pedro Díaz & Merino en Bureba y Rioja & UBIETO, Col. St ${ }^{\circ}$ D. C., doc. 100 \\
\hline
\end{tabular}




\section{CuAdro II. Merinos y adelantados en Bureba y Rioja. S.S. XIII, XIV y XV}

\begin{tabular}{|c|c|c|c|}
\hline Fecha & Nombre & Titulación & Fuente \\
\hline 1222 & Don Nuño de Aguilar & "el adelantado" & LIZOAIN, Huelgas, doc. 173 \\
\hline 1223 & Don Nuño de Aguilar & "iudex maior regis in Borovia" & ALAMO, Oña, doc. 434 \\
\hline 1224 & Diego Martínez de Zarratón & Adelantado de Rioja & UBIETO, C.St ${ }^{\circ}$., doc. 134 \\
\hline 1237 & Gonzalo Gonzalez & Adelandado de Bureba & GONZALEZ, Fernando III, 601 \\
\hline 1239 & Ferran Ruiz de Fervías & Adelantado en Rioja & LAMA, CDMR, T. IV, doc. 127 \\
\hline 1242 & Fernando Díaz de Grañón & $\begin{array}{l}\text { Merino de Tierra de Nájera } \\
\text { y de Rioja }\end{array}$ & LAMA, CDMR, T. IV, doc. 142 \\
\hline 1257 & Fernando Díaz de Rojas & Merino de Rioja & $\begin{array}{l}\text { GARCIA TURZA, Una nueva } \\
\text { visión..., doc. } 56\end{array}$ \\
\hline 1277 & Roy Fernández & Merino de Bureba y Rioja & ALAMO, Oña, doc. 666 \\
\hline 1282 & Diego Pérez & Merino de Bureba y Rioja & ALAMO, Oña, doc. 722 \\
\hline 1284 & Juan González de Bobadilla & Merino de Bureba y Rioja & OCEJA, Oña, doc. 254 \\
\hline 1285 & Pedro García de Leiva & $\begin{array}{l}\text { Merino de Bureba por J. Glez. } \\
\text { Bobadilla }\end{array}$ & OCEJA, Oña, doc. 287 \\
\hline 1289 & Gil Pérez de Briones & Merino de Bureba y Rioja & CANTERA, Miranda, doc. 43 \\
\hline 1290 & Martín Fernández de Soto & Adelantado de Bureba y Rioja & OCEJA, Oña, doc. 338 \\
\hline 1291 & Martín Fernández de Soto & Adelantado de Bureba y Rioja & OCEJA, Oña, doc. 358 \\
\hline 1301 & Martín Sánchez & Merino de Bureba y Rioja & CANTERA, Miranda, doc. 61 \\
\hline 1301 & Pedro Díaz de Río Cerezo & Merino de Bureba y Rioja & CANTERA, Miranda, doc. 61 \\
\hline 1302 & Ramiro García de Bañuelos & Merino de Bureba y Rioja & CANTERA, Miranda, doc. 61 \\
\hline 1331 & Diego Ortiz Calderón & Merino de Rioja & SILANES-RIPA, A.C.St ${ }^{\circ} D$. , doc. 82 \\
\hline 1335 & Ferrán González Herramélluri & Merino de Rioja & JIMENEZ, Cañas, doc. 120 \\
\hline 1335 & Juan López de Mendoza & Merino de Rioja & SILANES-RIPA, A.M.St'.D, doc. 26 \\
\hline 1335 & Juan Martínez de Soto & Merino de Bureba y Rioja & SILANES-RIPA, A.M.St ${ }^{\circ}$ D, doc. 26 \\
\hline 1338 & Fernando Díaz de Ubierna & Merino de Bureba y Rioja & OCEJA, Oña, doc. 671 \\
\hline 1339 & Juan Pérez de Valluércanes & Merino de Bureba y Rioja & OCEJA, Oña, doc. 675 \\
\hline 1341 & Juan González de Celada & Merino? & JIMENEZ, Cañas, doc. 126 \\
\hline 1342 & Juan Ochoa de Zancada & Merino de Bureba y Rioja & SILANES-RIPA, A.C.St'.D., doc. 94 \\
\hline 1345 & Juan Pérez de Valluércanes & Merino de Bureba y Rioja & OCEJA, Oña, doc. 704 \\
\hline $1350 ?$ & Alvar Díaz de Sotiello & Merino de Bureba y Rioja & $\begin{array}{l}\text { RUIZ GOMEZ, Formas pobl..., } \\
\text { doc. } 88\end{array}$ \\
\hline
\end{tabular}


LA MERINDAD DE BUREBA Y RIOJA EN LA EDAD MEDIA...

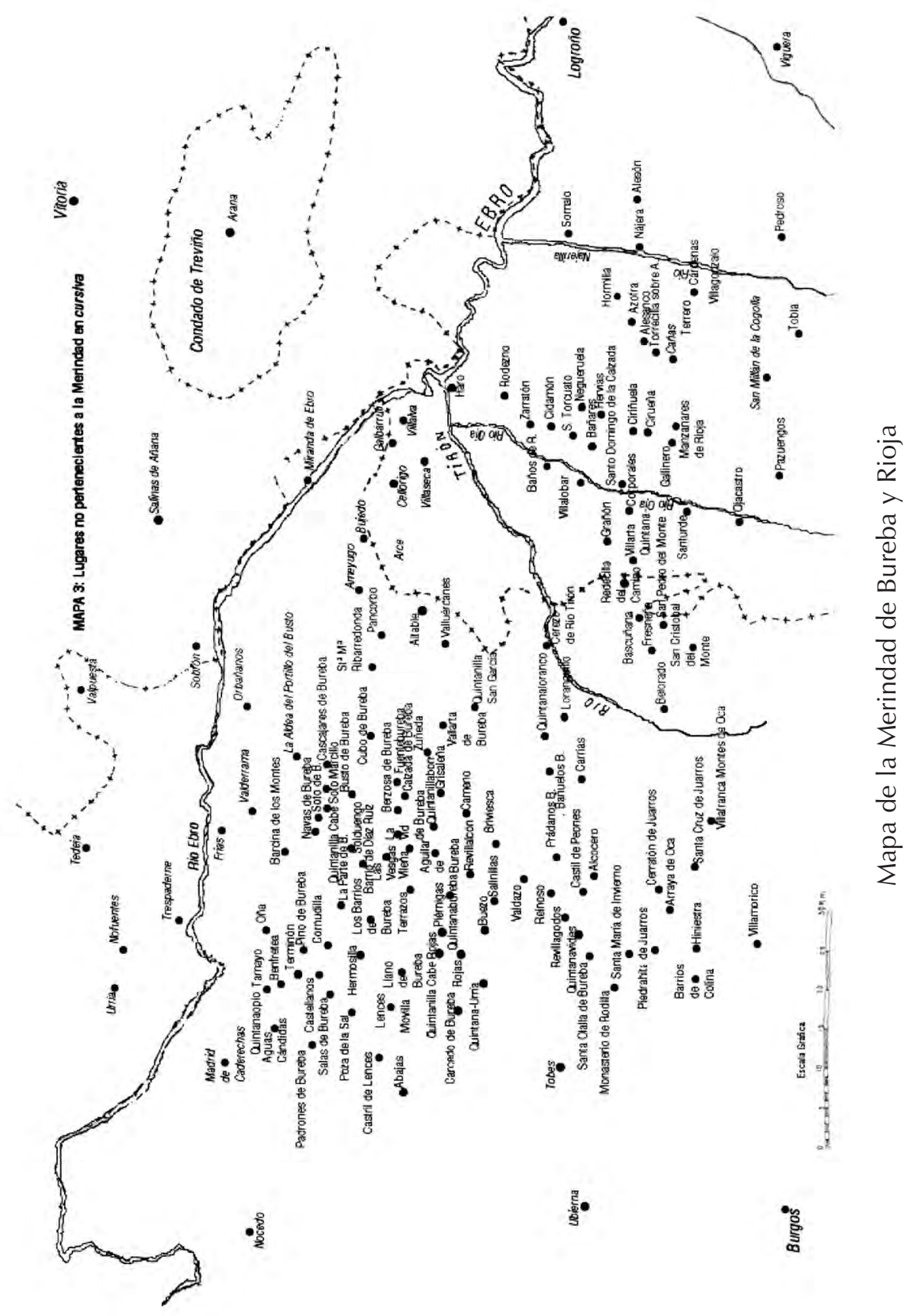

